Proc. of The Eighth Intl. Conf. On Advances in Applied Science and Environmental Technology - ASET 2018 Copyright $($ Institute of Research Engineers and Doctors, USA. All rights reserved.

ISBN: 978-1-63248-155-9 doi: 10.15224/978-1-63248-155-9-32

\title{
White-rot fungi and their enzymes in development of industrial effluent treatment systems
}

\begin{abstract}
Kavita Vasdev*
Abstract:

Industrial effluents containing wastewater from textile and dyestuff industries is one of the most difficult to be treated. Since it contains various kinds of synthetic dyes The strong color of these discharged dyes even at very small concentrations has a huge impact on the aquatic environment caused by its turbidity and high pollution strength: in addition toxic-degradation products can be formed, they can cause serious environmental pollution illustrating the need for a non-specific method of decolorization. The low biodegradability of these dyes

fungi not only decolorized the dyes but also degraded them as is evident from the shift in their UV-VIS absorption spectra. Linear increase in laccase production by all five fungi, was observed with a simultaneous increase in extent of decolorization, irrespective of the type of dye. The presence of the dyes in liquid medium had little or no effect on the mycelial growth, at the concentration tested. Three of these fungi were found to have capacity to decolorize as high as $6 \mathrm{~g} / \mathrm{L}$ concentration of these dyes. Furthermore, the fungi degraded these dyes without accumulating any phenolic compounds.
\end{abstract} due to, complex aromatic molecular structures, with most of the dyes being very stable to light, temperature and microbial attack, making them recalcitrant. Conventional waste water treatment is not efficient to remove recalcitrant dyestuffs from effluents. Several physical and chemical methods are effective but have high operating costs and limited applicability. Although, abiotic means of reduction of azo and other dyes exists but they require highly expensive catalysts and reagents. Hence there's an urgent need to develop treatment system for bioremediation of dye containing industrial effluents to reduce pollution in a non-toxic manner and provide environmentally friendly treatment technology for sustainable development. By far the single class of microorganisms most efficient in breaking down synthetic dyes is white rot fungi. These fungi are a class of microorganisms that are known to produce efficient enzymes capable of decomposing dyes under aerobic conditions. They produce various oxidoreductases that degrade lignin and a very wide range of pollutants; such as polychlorinated biphenyls (PCB) polycyclic aromatic compounds (PAH), pesticides, synthetic dyes, Industrial dyes. Owing to extracellular, non-specific, free radical based ligninolytic systems of WRF; they can completely eliminate a variety of xenobiotics, including synthetic dyes and industrial dyes giving rise to non-toxic compounds .In our studies, we evaluated the potential of SIX white-rot fungal strains (isolated from nature) in decolorizing various different classes of dyesSynthetic(Rhodamine, methyl orange), azo, Triphenylmethane dyes(Crystal violet, Malachite green) and other dyes(Xylidiene, Congo- red) in order to develop them in future as target organisms for treatment of industrial effluents. All the six fungal isolates were able to decolorize all dyes tested. All of them except $\mathrm{AKCH}$ showed considerably high rate of decolorization, removing more than $90 \%$ of the colour within 144 hours. All the fungal isolates showed high rates of decolorization, with KV10 and KV12 removing $76 \%$ color within 96 hrs. , KV10 and KV12 being, the most efficient in decolorizing the dyes, causing $74 \%$ and $72 \%$ decolorization of Crystal Violet within $48 \mathrm{hrs}$. All the
Keywords: Dye decolorization, white-rot fungi, synthetic dyes, laccase,

\section{*Department of Microbiology,Gargi College (University of Delhi)Siri Fort Road, New Delhi- 110049, INDIA}

\subsection{Introduction:}

Synthetic dyes are used for various industrial applications, such as textile dyeing or paper printing, cosmetics, leather dyeing, color photography, pharmaceuticals and food industries. These dyes represent a large group of chemically different compounds, which are classified by their chromophore into azo, anthraquinone, triphenylmethane, heterocyclic or pthalocyanine dyes (Eichlerova et al 2007). A significant proportion of these dyes enter the environment in waste water as industrial effluents. Many chemical dyes have been used increasingly in textile and dyeing industries because of their ease and cost effectiveness in synthesis, firmness and variety in color compared to that of natural dyes. Over 10,000 dyes with an annual production of over $7 \times 10^{5}$ metric tons are commercially available (Campos et al 2001). Approximately $50 \%$ of these dyes are released in the industrial effluents (Zollinger, 1991). The majority of synthetic dyestuffs are hardly removed from textile waste water by conventional waste water treatment, such as activated sludge (Shaul et al 1991) and physiological processes. Due to the low biodegradability of synthetic dyes, they can cause serious environmental pollutions, (Eichlerova et al 2006). The strong color of discharged dyes even at very small concentrations has a huge impact on the aquatic environment caused by its turbidity and high pollution strength: in addition toxic-degradation products can be formed (Moorthi et al 2007). Most dyes are very stable to light, temperature and microbial attack, making them recalcitrant compounds. Many of them are toxic, carcinogenic and mutagenic (Michael and Lewis 1985: Chung et al 1992). Moreover, the high volumetric rate of industrial effluents discharged in combination with increasingly stringent legislation; make the search 
for appropriate treatment technologies an important aspect (O’Neil et al 1999). Decolorization of dye waste water by the utilization of biodegradation abilities of white- rot fungi is the subject of many studies. White- rot fungi are a heterogenous group of micro-organisms but have in common the capacity to degrade lignin as well as other wood components (Kirk and Farrell, 1987). They are well-known for their outstanding ability to produce extracellular oxidative enzymes (laccase, lignin peroxidase, Manganese peroxidase, horse radish peroxidase) which are involved in the degradation of several dyes. (Unyayar at al 2005, Kersten et al 1990).To date, the majority of studies on biological decolorization have focused on white-rot fungal strains, due to their ability to produce lignin-modifying enzymes, which thanks to their lack of substrate specificity, are capable of degrading a wide range of xenobiotics(Wesenberg et.al. 2003). In this paper, we investigated white-rot fungi, isolated from nature, for their ability to decolorize, structurally diverse synthetic dyes- Acridine orange, Congo red, Crystal Violet and Xylidine .The decolorization was studied under static liquid culture conditions. An attempt was made to analyse, the effects of these dyes on fungal growth and the concomitant association of laccase production by these fungi and decolorization of synthetic dyes.

\section{Materials and Methods:}

\section{1: Isolation of micro-organism}

Fungi used in the study, were isolated from nature, as described (Vasdev K.,2011).Newly isolated fungi from nature were KV9, KV10, KV11, KV12, KVA5, and $\mathrm{AKCH}$. These fungal strains were grown 2\% Malt extract agar (MEA) media, containing Malt extract 20g/L, $\mathrm{Ca}(\mathrm{NO} 3) 2.4 \mathrm{H} 2 \mathrm{O} \quad 0.5 \mathrm{~g} / \mathrm{L}, \quad \mathrm{MgSO} 4.7 \mathrm{H} 2 \mathrm{O} \quad 0.5 \mathrm{~g} / \mathrm{L}$, $\mathrm{KH} 2 \mathrm{PO} 40.5 \mathrm{~g} / \mathrm{L}$, Agar 20g/L, pH 5.4 and incubated at 28 ${ }^{\circ} \mathrm{C}$ Pure cultures of these strains were maintained by repeated sub-culturing on MEA. These strains were stored at $4^{\circ} \mathrm{C}$ till use. All strains were examined microscopically for, mycelial characters, presence or absence of spores and clamp connections.

\subsection{Culture medium:}

All WRF were grown in $250 \mathrm{ml}$ Erlenmeyer flasks containing $50 \mathrm{ml}$ of sterile $2 \%$ Malt extract broth (MEB) containing $\mathrm{Ca}(\mathrm{NO} 3) 2 \quad .4 \mathrm{H} 20 \quad 0.5 \mathrm{~g} / \mathrm{L}, \quad \mathrm{MgSO} 4.7 \mathrm{H} 20$ $0.5 \mathrm{~g} / \mathrm{L}, \quad \mathrm{KH} 2 \mathrm{PO} 4$ 0.5g/L, Agar $20 \mathrm{~g} / \mathrm{L}, \mathrm{pH} 5.4$ and incubated at $28^{\circ} \mathrm{C}$. Each flask was inoculated with two $8 \mathrm{~mm}$ diameter fungal discs, obtained from the periphery of the actively growing fungal cultures on MEA plates and incubated at $28^{\circ} \mathrm{C}$. After 8 days of growth, liquid media, $1 \mathrm{ml}$ of Acridine orange, Congo red, Crystal violet and 2,5- xylidine $(1 \mathrm{mg} / \mathrm{ml})$ was added to each flask, containing respective grown fungal culture. The time of addition of dyes in the grown culture flask was considered to be day zero.

\subsection{Decolorization Assays:}

Decolorization of all four dyes in liquid media was measured in culture filtrates (three replicate flasks), after aseptically removing $1 \mathrm{ml}$ of culture filtrate from each. The change in absorbance was monitored spectrophotometrically at their maximum wavelength (590nm for crystal violet, 498nm for Congo red $542 \mathrm{~nm}$ for xylidine\& $485 \mathrm{~nm}$ for Acridine orange). The uninoculated Malt extract broth with respective dye served as abiotic control. The decolorization efficiency was determined using the following equation:

Decolorization $(\%)=[\{(\mathrm{A} \lambda$ initial $-\mathrm{A} \lambda$ final $/$ $A \lambda$ initial $\} X 100]$

Where, $A \lambda$ initial $=$ Absorbance of dye in uninoculated control,

$A \lambda$ final $=$ Absorbance of dye in inoculated culture flasks.

\subsection{Enzyme Assays:}

The $250 \mathrm{ml}$ Erlenmeyer flasks with $50 \mathrm{ml}$ of MEB were inoculated in same way as for decolorization assay. Enzyme activity was measured in culture filtrates from replicate flasks, obtained after mycelia removal by filtration through filter paper. Laccase activity was determined spectrophotometrically by monitoring increase in absorbance at $470 \mathrm{~nm}$ due to oxidation of guaiacol according to Vasdev\&Kuhad (1994). Heat killed enzyme was used as control. The change in $0.01 / \mathrm{ml} / \mathrm{min}$ was defined as $1 \mathrm{U}$ of laccase activity.

\subsection{Determination of biomass production:}

Biomass production in liquid media was evaluated by determining the dry mass of mycelia .Mycelia were harvested from liquid cultures by filtration through what man filter paper no.1, dried at $80^{\circ} \mathrm{c}$ for 48 hours and weighed.

\section{Results:}

The fungal isolates, when observed microscopically, showed the presence of clamp connections, the characteristics feature of basidiomycetous fungi.

All newly isolated white rot fungi from natural sources, were basidiomycetes (namely KV9, KV10, KV11, KV12, $\mathrm{KVA5}$, and $\mathrm{AKCH}$ ). All the strains grew well on $2 \%$ Malt extract agar medium.

3.1 Dye decolorization by fungi in liquid culture:

All four synthetic dyes Xylidine, Congo Red, Acridine Red and Crystal Violet, were found to be decolorized by the sixfungi isolated from nature, though to different extents (Fig 1). Among the four dyes tested, Crystal violet was decolorized fastest (fig 4) showing $90 \%$ decolorization within 96 hours, whereas acridine orange was decolorized slowest (Fig 2).Among the six fungi tested, all of them except $\mathrm{AKCH}$ showed considerably high rate of decolorization, removing nearly $90 \%$ of the color within 144 hours (Fig 1). KV10 \& KV12 were most efficient removing $76 \%$ \& $74 \%$ Crystal Violet within 48 hours of incubation (Fig 4) and also showing maximum decolorization of other dyes as well.All the six fungi decolorizing the synthetic dyes exhibited laccase 
Proc. of The Eighth Intl. Conf. On Advances in Applied Science and Environmental Technology - ASET 2018 Copyright $\odot$ Institute of Research Engineers and Doctors, USA. All rights reserved.

ISBN: 978-1-63248-155-9 doi: 10.15224/978-1-63248-155-9-32

production. The fungal isolates KV10 \& KV12 which exhibited maximum decolorization, and were most efficient in decolorizing synthetic dyes, also showed maximum laccase production $29 \mathrm{U} \& 33 \mathrm{U}$ during decolorization on liquid malt extract broth supplemented with xylidine.

There was correlation between extent of decolorization and laccase production, by all six fungi. Linear increase in laccase production was observed with a simultaneous increase in extent of decolorization, by all six fungi tested, irrespective of the type of dye ( Fig 6,7,8,9) indicating the involvement of laccase in decolorization of synthetic dyes.

There was little or no effect of these synthetic dyes on the growth of the fungus, at the concentration tested as shown by the dry weight at the end of decolorization, when compared with fungi grown in the absence of the dye (Table 2).

\section{Discussion:}

The present study investigated the abilities of six basidiomycetes isolated from nature to decolorize various synthetic dyes in liquid media. Structurally diverse dyes were decolorized almost completely (nearly $90 \%$ ) within six days (144 hours) by all six fungi. The rate of decolorization of various dyes varied, which can be attributed to differences in their structural complexity. Structurally different dyes were decolorized to different extent (Fig1) Among the Azodyes,xylidine (mono azo dye) was decolorized more efficiently than congo red (diazo dye). This can be attributed to the presence of diazo bond in congo red which is more difficult than monoazo bond. The degradation of the azo dye involves aromatic cleavage, which depends on the identity, number and position of functional groups in the aromatic region, and the resulting interaction with the azo bonds.( Spadaro et al 1992;).Fungal isolate KV10 and KV12 were most efficient in decolorizing all the dyes up to $95 \%$. The present study also showed that the two most efficient dye decolorizing fungal strain KV10 \& KV12 also showed maximum laccase production. This significant positive correlation observed between increase in laccase production and extent of decolorization of dyes, by all six fungi indicates the involvement of laccase in degradation of synthetic dyes. It has also been reported by Diwaniyan S. et al 2009, Vasdev et al 1995, Vasdev and Kuhad 1994.This is not surprising given the structural similarity of most commercially important dyes to lignin (sub)structures, which are amenable to transformation, by ligninolytic enzymes, particularly laccases (Wesenberg et. al 2003)

Despite structural variations in the dyes tested, none of them showed any significant effect on the growth of these fungi as is evident from their biomass at the end of decolorization period (Table 2). This indicates that the fungi are able to neutralize or degrade these dyes without forming any toxic intermediates, which could hinder the growth of these fungi.

Therefore, these fungi could be easily exploited in future, for biodegradation of xenobioticsand other industrial effluents.

\section{Conclusion}

The present study with six natural fungal isolates, all of them highly efficient in decolorizing synthetic dyes, (with varied structures) within 144 hours, with simultaneous laccase production, and little or no effect on growth of these fungi, at the concentration tested, shows great promise for future biotechnological applications of these fungi, not only in decolorizing the dyes but also in degradation of xenobiotics and potential applications of laccases in bioremediation.

\section{Acknowledgements}

The author gratefully acknowledges University Grants Commission for the research grant F.No. 33216/2007(SR)], for funding this research and Principal, Gargi College for providing Infrastructural support.

\section{Bibliography}

1.Campos, R., Kandelbauer, A., Robra , K.H., CavacoPaulo, A., \&Guebitz, G. M. (2001).Indigo degradation with purified laccase from Trameteshirsutaand Sclerotiumrolfsii.J Biotechnol,89,131-139.

2. Chung KT, Stevens SE 1993. Decolorization of azo dyes by environmental micro-organisms and Helminths. Environ. Toxicol. Chem. 12: 2121-2132.

3.Eichlerova,I.,Homolka,L. and Nerud.,F.2006.Synthetic dye decolorization capacity of white rot fungus Dichomitussqualens, Bioresource Technol. ,97,21532159.

4. Eichlerova ,I., Homolka,L. and Nerud.,F.2007. Decolorization of high

concentrations of synthetic dyes by the white rot fungus Bjerkanderaadustastrain CCBAS 232 Dyes and Pigments, 75, 38-44.

5.Kersten, P.J. et al. 1990.Comparisonoflignin peroxidase, horseradish-peroxidase and laccase in the oxidation of methoxybenzenes. Biochem. J. 268, 475480.

6.Kirk TK, Farrell RL 1987. Enzymatic combustion: The microbial degradation of lignin. Ann. Rev. Microbiol. 41: 465-505.

7. Kuhad, R.C., N., Tripathi, K.K., Singh, A., \&Ward, O.P., 2004. Developmentsinmicrobial methods for the treatments of dye effluents. Adv Appl. Microbiol, $56,185-213$

8. Michaels.G.B., Lewis, D.L., 1985. Sorption and toxicity of azo and triphenylmethane dyes to aquatic microbial populations .Environ Toxicol Chem. 4,45-50.

9. O'Neill C, Hawkes FR, Hawkes DL, Lourenco ND, Pinheiro HM, Delee W 1999. Colour in textile effluents: sources, measurement, discharge consents and simulation: a review. J ChemTechnolBiotechnol74:10091018. 
10. Diwaniyan, S.,Kharb,D., C. Raghukumar.and R.C.Kuhad,2009. Decolorization of synthetic dyes and textile effluents by basidiomycetousfungi. Water, Air Soil Pollution DOI 10.1007/s11270-009-0263-x.

11.Sathiya moorthi, P., Periyarselvam, , Sasikalaveni, A. Murugesan, K., andKalaichelvan,.2007.Decolorization of textile dyes and their effluents using white rot fungi. African Journal of Biotechnology Vol. 6 (4), pp. 424429.

12.Shaul, G.M., Holdsworth, T.J., Dempsey, C.R., Dostall, K.A., 1991.Fate of water soluble azo dyes in the activated sludge process. Chemosphere 22,107-119.

13. Spadaro, J.T., Gold,M.H., and Renganathan,V. 1992. Degradation of azodyes by the lignin degrading fungus Phanerochaetechrysosporium. Appl. Environ. Microbiol., 58,2397-2401.

14. Unyayar A, Mazmanci MA, Atacag H, Erkurt EA, Coral G 2005. A drimaren blue X3LR dye decolorizing enzyme from Funaliatrogii: one step isolation and identification. Enzy. Microbial Technol. 36: 10-16.

15. Vasdev K., Kuhad, R.C. 1994.Decolorization of Poly R-478 (PolyvinylamineSulfonateAnthrapyridone) by Cyathusbulleri. Folia Microbiol 39 (1), 61-64 (1994).

16.Vasdev K., Kuhad, R.C., Saxena,R.K.1995.Decolorization of triphenylmethane dyes by the Bird's Nest Fungus Cyathusbulleri. Curr.Microbiol.30,269-272.

17.Vasdev K.,2011 . "Decolorization of Triphenylmethane dyes by six White- rot fungi isolated from nature". Journal of Bioremediation and biodegradation

18. Zollinger, Heinrich. 1991. Syntheses, Properties and Applications of Organic Dyes and Pigments. Color Chemistry $496 \mathrm{pp}$

19. Wesenberg, D., Kyriakidos, I., and Agathos,S.N.(2003).White-rot fungi and their enzymes for the treatment of industrial dye effluents. Biotechnol Adv.,22,161-187.
Fig 1

Decolorization \% at 144 hours with all fungal strains

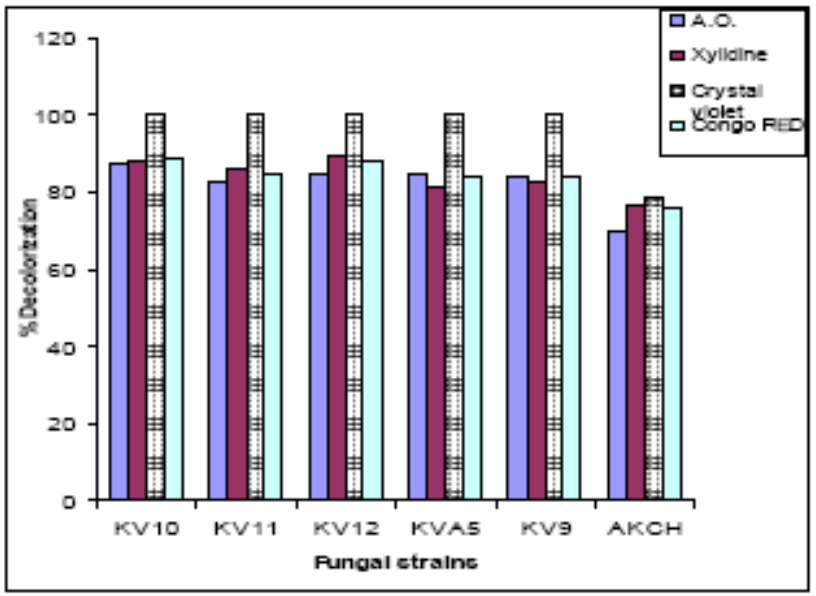

Fig 2

Decolorization $\%$ of Acridine orange

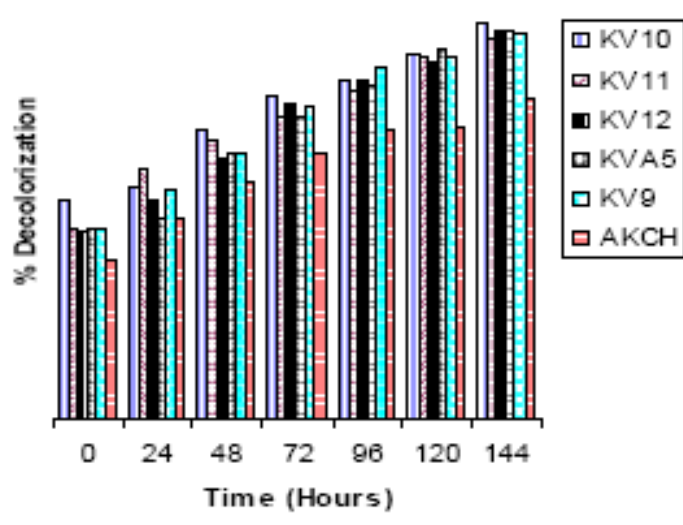


Proc. of The Eighth Intl. Conf. On Advances in Applied Science and Environmental Technology - ASET 2018 Copyright $\odot$ Institute of Research Engineers and Doctors, USA. All rights reserved.

ISBN: 978-1-63248-155-9 doi: 10.15224/978-1-63248-155-9-32

Fig 3

Decolorization $\%$ of Xylidine

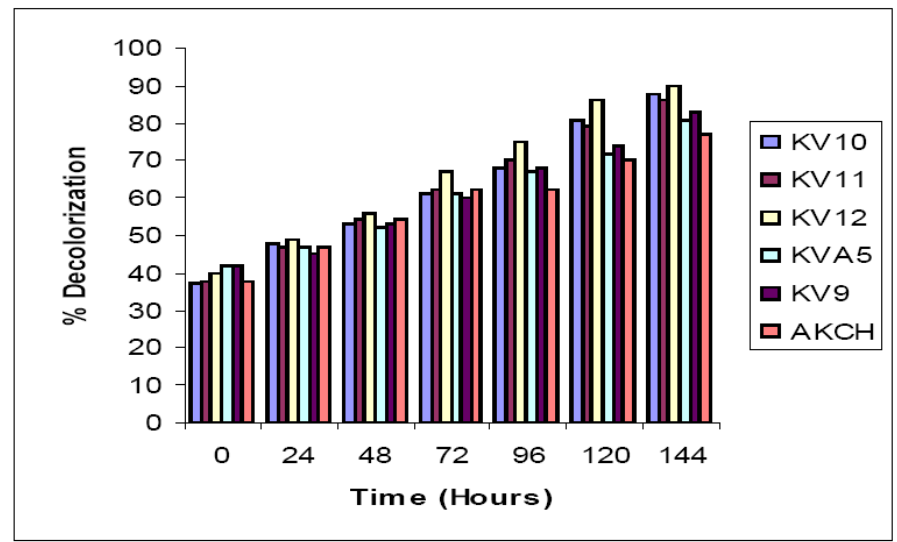

Fig 4

Decolorization \% of Crystal Violet

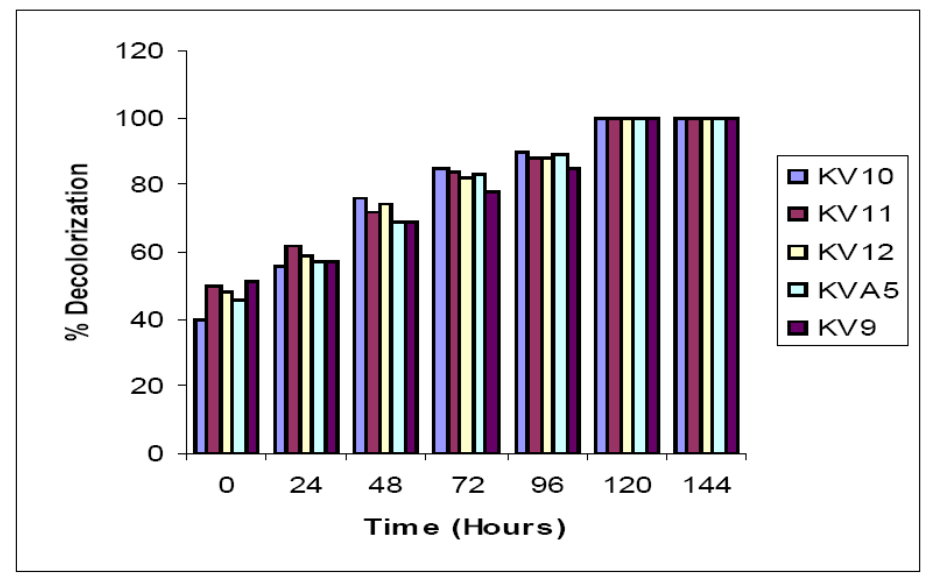

Fig 7

Laccase production by fungi on MEB + Acridine orange

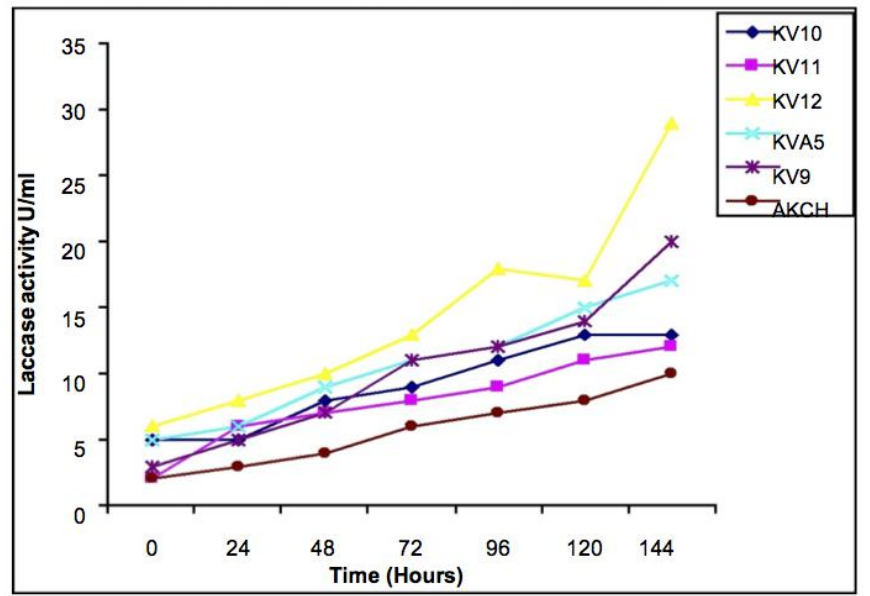

Fig 5

Decolorization \% of Congo red

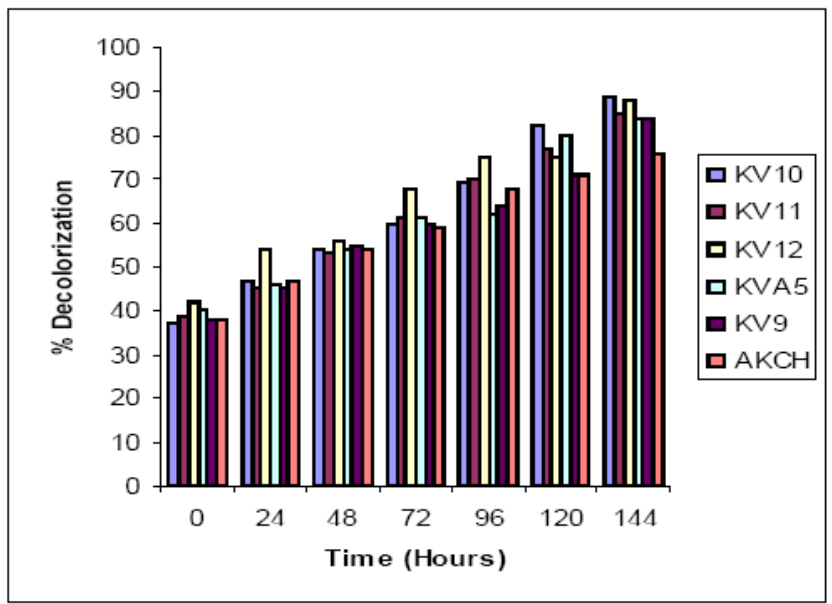

Fig 6

Laccase production by fungi on MEB+ Xylidine

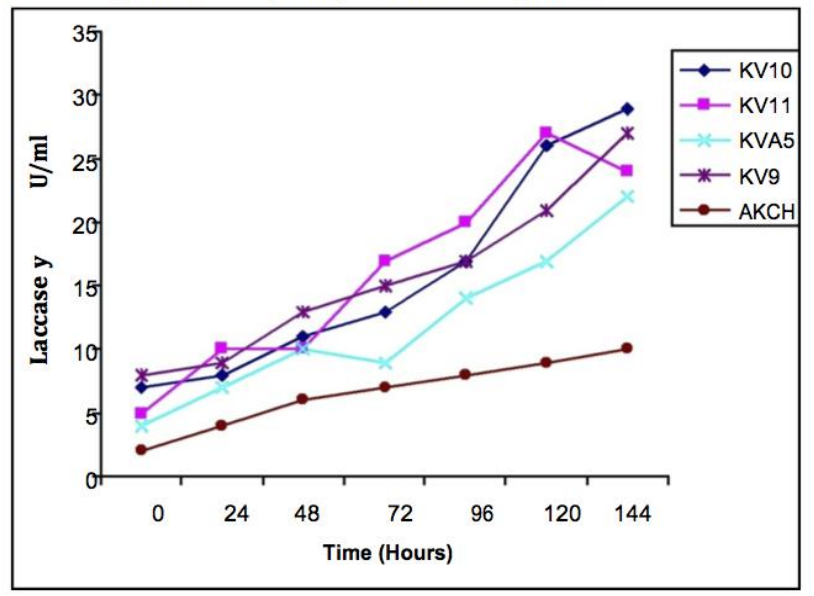


Proc. of The Eighth Intl. Conf. On Advances in Applied Science and Environmental Technology - ASET 2018 Copyright (C) Institute of Research Engineers and Doctors, USA. All rights reserved.

ISBN: 978-1-63248-155-9 doi: 10.15224/978-1-63248-155-9-32

Fig 8

Laccase production by fungi on MEB + Congo red

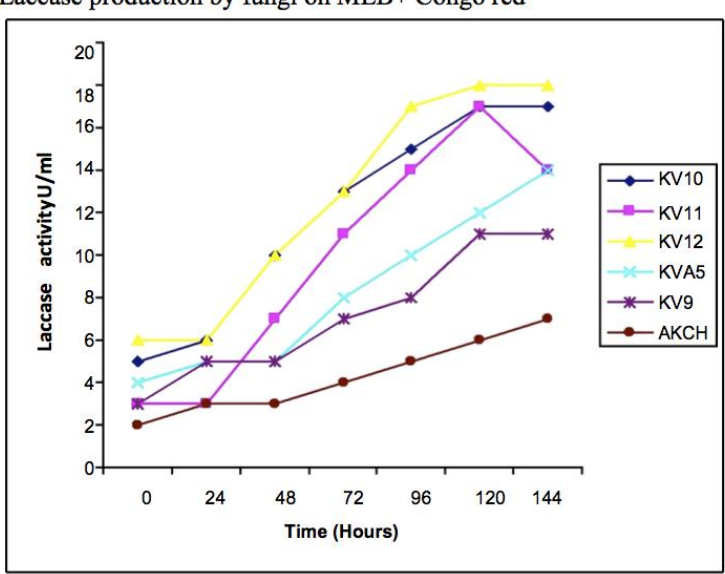

Fig 9

Laccase production by fungi on MEB+ Crystal Violet

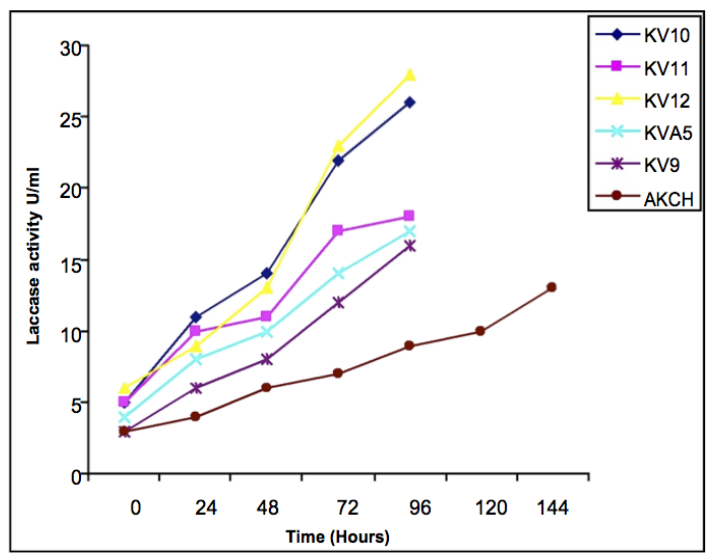

Table no. 1

Chemical structure of Dyes

\begin{tabular}{|c|c|c|}
\hline Dyes & Acridine orange & Chemical Structure \\
\hline Congo red & & \\
\hline Crystal Violet & -xylidine &
\end{tabular}

Table no. 2

Biomass (in Grams) at $15^{\text {th }}$ day of growth on dyes, (C.V. Crystal Violet, XYL Xylidine, C.R. Congo red, A.O. Acridine orange)

\begin{tabular}{|l|c|c|c|c|c|}
\hline Fungi & MEB & MEB+C.V. & MEB+XYL & MEB+C.R. & MEB+A.O. \\
\hline KV10 & 0.611 & 0.601 & 0.61 & 0.621 & 0.604 \\
\hline KV11 & 0.225 & 0.213 & 0.22 & 0.224 & 0.226 \\
\hline KV12 & 0.584 & 0.598 & 0.286 & 0.583 & 0.589 \\
\hline KVA5 & 0.414 & 0.399 & 0.395 & 0.413 & 0.412 \\
\hline KV9 & 0.131 & 0.146 & 0.135 & 0.135 & 0.125 \\
\hline AKCH & 0.146 & 0.140 & 0.136 & 0.157 & 0.151 \\
\hline
\end{tabular}

